\title{
Clusters, Chains and Compliance: Corporate Social Responsibility and Governance in Football Manufacturing in South Asia
}

\author{
Peter Lund-Thomsen \\ Khalid Nadvi
}

\begin{abstract}
A recent concern in the debate on corporate social responsibility (CSR) in developing countries relates to the tension between demands for CSR compliance found in many global value chains (GVCs) and the search for locally appropriate responses to these pressures. In this context, an emerging and relatively understudied area of interest relates to small firm industrial clusters. Local clusters offer the potential for local joint action, and thus a basis for improving local compliance on CSR through collective monitoring and local governance. This article explores the interrelationship between global governance, exercised through GVC ties, and local governance, via cluster institutions, in ensuring compliance with CSR pressures. It undertakes a comparative analysis of two leading export-oriented football manufacturing clusters in South Asia that have both faced common challenges on child labour. The article shows that both forms vertical and horizontal governance have played a part in shaping the response of the two clusters on child labour. Moreover, these two distinct forms of governance have also led to quite differentiated outcomes in terms of forms of work organization and child labour monitoring. This raises broader questions on how global CSR demands can locally be better embedded and the conditions under which football stitchers labour in these new work forms.
\end{abstract}

KEY WORDS: corporate social responsibility, global value chains, industrial clusters, South Asia

ABBREVIATIONS: AA: Atlanta Agreement; CSDO: Child and Social Development Organization; CSR: Corporate Social Responsibility; DFID: Department for International Development; FIFA: The World Football Federation; GVC: Global Value Chain; ILO: International Labor Organization; IMAC: Independent Monitoring Association for Child Labor; IPEC: International
Programme for the Elimination of Child Labor; MSI: Multi-Stakeholder Initiative; NGO: Non-Governmental Organization; OEM: Original Equipment Manufacturer; PILER: Pakistan Institute of Labor Research and Education; SAHEP: Select-Anwar Khawaja Health and Education Program; SCCI: Sialkot Chamber of Commerce and Industry; SCF: Save the Children Fund; SGFI: Sports Goods Foundation of India; SGMEA: Sports Goods Manufacturers and Exporters AssociationUNIDO: United Nations Industrial Development Organization; UNICEF: United Nations Children Fund; WFSGI: World Federation of Sports Goods Industry

\section{Introduction}

A recent concern in the debate on corporate social responsibility (CSR) and its impacts in developing countries relates to the tension between demands for compliance with codes of conduct found in many global value chains (GVCs) and the search for locally appropriate responses to these pressures. ${ }^{1}$ On one hand, internationally branded companies are concerned with negative media reports about the use of child labour, poor working conditions, worker rights abuses, and other forms of 'unethical' behaviour in their supply chains that may dent their public image. On the other hand, local suppliers in the developing world fret about the added costs associated with CSR compliance, the simultaneous pressures from buyers to reduce prices, and the relevance of external CSR demands to their particular social and cultural contexts (Barrientos, 2008; De Neve, 2009; Neilson and Pritchard, 2009). How might these contradictory global and local pressures be 
resolved, especially in ways that appear appropriate to the local context?

In this global-local nexus linking Northern CSR concerns to production sites in the developing world, an emerging and yet relatively understudied area of interest relates to local production areas - the so-called small firm industrial clusters (Accountability, 2006). Many of the most powerful examples of local industrial competitiveness in the developing world emanate from such forms of industrial organization (Schmitz and Nadvi, 1999). Industrial clusters in some developing countries have successfully overcome the constraints facing individual small firms, and aggressively compete alongside large firms in demanding global markets. Potential clustering advantages include not only the economies of scale and scope, agglomeration gains, but also the possibility for joint action. Cluster promotion has become an important plank of national and international policy support for local industrial development in many parts of the world (Altenburg and Meyer-Stamer, 1999; Ceglie et al., 1999; OECD, 1999). Yet, despite this interest, we have little information on how CSR pressures are addressed in cluster settings.

In this article, the authors try to develop a new way of exploring the interplay between GVC governance and local cluster governance in ensuring compliance with CSR standards. While the CSR literature covers a wide range of issues, ${ }^{2}$ we are particularly interested in labour standards, and specifically on child labour, as a subset of CSR codes. Our core questions are: Does horizontal cluster governance - in the form of collective action through cluster institutions - enhance CSR compliance by reducing monitoring costs to individual firms and providing collective oversight of cluster firms' CSR behaviour? Or does vertical GVC governance ensure greater adherence with CSR standards as Northern lead firms dictate the terms and processes under which local developing world suppliers produce?

We address these questions through a comparative study of two particular South Asian clusters that stand out in the manufacture of footballs - Sialkot in Pakistani Punjab and Jalandhar in Indian Punjab. These export-oriented clusters are important players in the global sporting goods industry. The global sports industry is marked by the presence of the well-known global brands such as Nike and Adidas that source from suppliers across the developing world through complex GVC ties. It is also an industry that has faced substantial international pressures on labour standards, especially child labour (Lund-Thomsen and Nadvi, 2010; Nadvi, 2008) Complying with these standards is thus a prerequisite for developing country suppliers if they want to access the high end of the sports goods markets in North America and Europe. In reality, however, the relevance and effectiveness of compliance with such CSR demands remain highly contested.

We argue that the complex interaction between vertical GVC governance pressures and local horizontal cluster governance responses in Sialkot and Jalandhar have resulted in divergent ways of institutionalizing CSR concerns in both clusters. In Sialkot, the threat of boycotts, the compliance demands of leading brand buyers and intense scrutiny from international media and advocacy NGOs have been instrumental in promoting a structural transformation of production. Diffused home-based football stitching has been replaced in large measure by a more centralized, and more easily monitored, model of production undertaken within designated stitching centres. At the same time, a history of some collective action in Sialkot has facilitated the development of a cluster-wide CSR monitoring mechanism. In contrast, while the much smaller Jalandhar cluster has also faced scrutiny on child labour, the cluster has only recently developed a strong collective action institution. The fact that its leading buyers are not the top brands in sports goods has meant that it has neither faced the same extent of monitoring by advocacy groups as experienced in Sialkot, nor had to undertake the same degree of restructuring of production arrangements at the behest of brand buyers. Thus, home-based stitching continues to be the dominant model of football stitching in Jalandhar.

This study draws on primary field research conducted between July 2007 and July 2008. During this period, several visits were undertaken to both clusters alongside research in Europe and the United States. Interviews took place with a wide range of key informants, local institutions and firms in the two clusters. In Sialkot, this involved four large, three medium-sized and four small enterprises. In Jalandhar, we interviewed five medium-sized and 
four small enterprises. While these samples are clearly not enough to generalize our findings to all firms within each clusters as would have been possible with the use of a large quantitative survey, we used a maximum variation methodology to purposefully select interviews with first-tier suppliers that were integrated into different types of value chains, serving different types of branded and nonbranded buyers to understand the operation of CSR compliance pressures in both Sialkot and Jalandhar. In addition, repeated discussions took place with local 'collective action' institutions in each cluster. In Sialkot, this included the Sialkot Chamber of Commerce and Industry (SCCI), the Independent Monitoring Association for Child Labour (IMAC), and the Child and Social Development Organization (CSDO), a sub-body of the SCCI. In Jalandhar, interviews were conducted with the Sports Goods Foundation of India (SGFI) and the Sports Goods Manufacturers and Exporters Association (SGMEA). We also met representatives of leading local NGOs involved in social protection or advocacy work related to improving the work conditions and livelihoods of football stitchers. In Sialkot, this included Bunyad, Sudhaar, Select-Anwar Khawaja Health and Education Program (SAHEP), as well as Pakistan Institute of Labour Education and Research (PILER). In Jalandhar, this included REACH, the Lions Club and Volunteers for Social Justice. In addition, we met the trade union representatives in Sialkot from the cluster's former leading firm, Saga Sports, and the Pakistan Workers Federation. We also spoke to representatives from international policy actors operating in the two clusters, including representatives from the International Labour Organization (ILO) and the United Nations Industrial Development Organisation (UNIDO) in Lahore and Sialkot and the Department of Labour, Province of Punjab, Pakistan, as well as the Deputy Commissioner of Labour, Jalandhar, India and former and present UNIDO staff in New Delhi and Jalandhar, who had worked with the cluster in the last 5 years. Outside South Asia, we met senior officials at the ILO and the World Federation of the Sporting Goods Industry (WFSGI) in Switzerland. We also interviewed senior personnel of leading brands to understand their sourcing and CSR practices in relation to the two clusters. These included Nike (US), Adidas (Germany), Mitre/Pentland (UK), and smaller brands such as Select Sports (Denmark) and Fairdeal Trading (UK). Finally, we had in-depth conversations with former or present representatives of international NGOs, including Save the Children-UK, Dalit Solidarity Network International, and the Indian Commission of the Netherlands that had an interest in or worked on child labour issues in each cluster.

The article is structured as follows. First, we outline the theoretical linkages between the GVC, the industrial cluster and CSR literatures. We then describe the similarities and differences that exist in the internal organization and external value chain linkages of the Sialkot and Jalandhar clusters. We then undertake a comparative analysis of how GVC governance and local cluster governance on CSR issues have been institutionalized in the two clusters. Finally, we highlight the main findings of our study and the research and policy implications that arise from our analysis.

\section{Global value chains and CSR compliance in industrial clusters: exploring the linkages}

In this section, we explore the potential for a fruitful interaction between the GVC, industrial cluster and CSR literatures in exploring how CSR compliance might be enhanced in industrial clusters in the developing world. A number of authors have explored the links between local industrial clusters and GVCs (see e.g. Bair and Gereffi, 2001; Humphrey and Schmitz, 2002; Nadvi, 2004; Pietrobelli and Rabellotti, 2007; Schmitz, 2004). However, the literature on the theoretical linkages between these forms of industrial organization and CSR remains sparse (Nadvi, 2008). We begin by outlining the GVC and industrial cluster approaches, and then assess their conceptual linkages with the CSR literature.

\section{The global value chain approach}

The GVC model maps the complex links between globally dispersed producers and global lead firms. A core focus in the GVC literature is theorizing how global lead firms exercise power in their relationships with their suppliers (Altenburg, 2006; Gereffi, 1999; 
Gereffi et al., 2005; Gibbon and Ponte, 2005; Humphrey and Schmitz, 2002; Nadvi, 2008). The GVC approach underlines the critical role of global lead firms in structuring value chain ties by coordinating the processes and organization of global production and distribution, thereby exercising 'power' over local actors. Understanding how global lead firms exercise 'asymmetrical power' over dispersed global suppliers has required the analytical framework of transaction cost economics. 'Reducing the costs of organizing the chain, coordinating dispersed and varied suppliers and dealing with concerns such as asset specificity lie at the heart of what lead firms do. This can either take place through market transactions at one extreme or through internalized hierarchical forms of organization at the other extreme. In between these extremes lie a number of distinct forms of network relationships' (Nadvi, 2008, p. 331). In the GVC governance framework suggested by Gereffi et al. (2005), the specific governance outcome in a given value chain is determined by the capability of suppliers, the nature and complexity of the transaction involved, and the ability to which information can be codified. They identify five types of value chain governance: market-based ties at one extreme and hierarchy at the other with modular networks, relational networks and captive networks as distinct network relationships in-between. While this framework has come in for criticism (see Coe et al., 2008; Ponte and Gibbon, 2005), it continues to provide a useful analytical handle on inter-firm governance within GVC relationships.

Another central concern in the GVC literature relates to how local producers in developing countries might improve their position in the world economy by inserting themselves into GVCs. For developing country producers, a key challenge is thus how they link up to these lead buyers in ways that enable them to access export markets, adopt new technologies and acquire more efficient and modern methods of production and management through knowledge transfers (Bair and Gereffi, 2001). However, as newer low-cost producers enter the global economy, developing country suppliers within GVC relationship increasingly find themselves under pressure to reduce costs further, to seek out greater efficiencies and to be ever-more competitive.
The GVC literature identifies two divergent paths through which local producers can their improve competitiveness. The first, the 'high road' to competitiveness, involves local producers increasing their own profits and returns to labour by engaging in product upgrading ('making better products'), process upgrading ('making them more efficiently'), functional upgrading ('moving from lower valueadded product assembly and manufacturing into design and branding functions'), or chain upgrading ('using the skills gained by working in other sector to gain competitive advantage in other sectors') (Schmitz, 2004). The second path, the 'low road', implies a 'downgrading' strategy that includes squeezing labour (by offering lower wages and poorer working conditions), moving into lowervalue-added activities, or failing to meet environmental and labour standards (for example, not investing in pollution control) to compete against other more efficient producers in the developing world (Gibbon and Ponte, 2005).

Downgrading is seen as a short-term (and undesirable) strategy in the GVC literature given that any competitive advantage is likely be eroded in the long-run by the large number of producers (and countries) that are capable of engaging in fierce price competition on the basis of cheap and abundant labour. Instead, most academic and policy discussions on clusters and GVCs have focused on how industrial upgrading might occur, and how best might this be promoted. The GVC literature emphasizes the role of lead firms in determining the prospects for developing country suppliers to upgrade. This underscores the importance of 'vertical' value chain governance. The industrial cluster literature, on the other hand, stresses that local inter-firm cooperation is important towards promoting industrial upgrading. This underlines the significance of 'horizontal' cluster governance.

\section{The industrial cluster approach}

Clusters are geographical spaces, or regions, where firms in similar and cognate activities are located within well-defined spatial boundaries wherein proximity promotes a range of economic benefits (Porter, 1998). These gains include agglomeration benefits that generate economies of scale and scope 


\section{Clusters, Chains and Compliance}

for small clustered producers. Thus, economic externalities arise from the presence of a critical mass of firms, suppliers and a skilled labour pool within the confines of the cluster, as well as through flows of information, knowledge and skills within the cluster. Hence, small clustered producers are able to overcome many of the limitations imposed upon them by their size. In addition, clustering offers the possibility for local joint action. This can result in competitive advantages for clustered producers that lie beyond their capacities as individual producers (Schmitz and Nadvi, 1999). Joint action, however, is not a necessary outcome of clustering, and it can be very difficult to motivate cluster firms to undertake such forms of cooperation as they often perceive themselves as competitors. Nevertheless, where joint action takes place, gains to cluster-based actors can be significant. This often arises in the face of external shocks where, through joint action and co-operation, local firms find ways to confront common challenges. Together, these potential gains from clustering, agglomeration economies and action are captured in the concept of collective efficiency (Nadvi, 1999a, b; Schmitz, 1995). ${ }^{3}$

Recent analytical attempts have focused on how the GVC and industrial cluster literatures may be reconciled by specifying how particular forms of value chain governance appear to enable or disable the prospects of local producers to upgrade (Humphrey and Schmitz, 2002). The emerging consensus appears to be that developing country producers may experience relatively fast process and product upgrading by linking up with global lead firms but that the latter firms will attempt to prevent developing country producers from encroaching on their core competence -namely the design, branding and marketing of their products (Schmitz, 2006).

\section{Global value chains, industrial clusters and CSR}

While the GVC and industrial cluster literatures have for long been inter-related, less attention has been paid to the way in which the notion of CSR, particularly corporate codes of conduct, impacts upon, and is itself impacted by, the relationships between GVCs and industrial clusters. Recently, there has been much emphasis in the GVC literature on investigating how global lead firms implement codes of conduct throughout their supply chains and exploring how CSR codes affect working conditions (Barrientos and Smith, 2007; ETI, 2006; Locke and Romis, 2007; Locke et al., 2007, 2009; Nelson et al., 2007). Similarly, the industrial cluster literature has emphasized that compliance with quality, social and environmental standards is often a necessary but not sufficient condition for continued market access in the North. It has also pointed to the role that joint action, through industry associations and multistakeholder initiatives, can play in facilitating clusterwide compliance with such standards (Kennedy, 1999, 2006; Lund-Thomsen and Nadvi, 2010; Nadvi, 1999a, b, 2004; Tewari and Pillai, 2005).

A key aspect missing from these studies, however, is whether the design, implementation, monitoring and impact assessment of codes of conduct are more effectively achieved through vertical GVC governance or horizontal local cluster governance. Moreover, little attention has been paid to whether and how local cluster-based actors might negotiate the norms and values codified within the CSR requirements of global lead firms. Instead, clusterbased actors are portrayed as being 'standard takers' as opposed to 'standard setters' (Humphrey and Schmitz, 2002; Nadvi, 2004, 2008).

The value chain framework has argued that in 'captive' supply chains, the lead firm (the external buyer) exercises almost complete control over their suppliers in terms of what is produced, where, when, how, by whom, in what quantity and at what price (Gereffi et al., 2005). In the ethical trading and ethical sourcing literature, it is also assumed that the lead firms, often international retail brands or global brand supermarkets, operating in highly CSRsensitive industries, design and enforce compliance with CSR standards in their captive supply chains (Barrientos, 2008). Much effort has thus been devoted to analysing the contents of the codes of conduct of lead firms, the types of monitoring mechanisms used to verify their implementation, and (to a lesser extent) how they are operationalized on the ground in developing countries (see e.g. Barrientos and Smith, 2007; Fransen and Kolk, 2007; Kolk and Tulder, 2001).

However, there may be grounds for questioning the influence that international lead firms are capable of exercising in relation to determining which type of CSR values and norms should dominate 
production in industrial clusters. First, it may only be a small minority of firms in a given cluster, which are integrated in captive chains dominated by globally branded lead firms (see also Bazan and NavasAlemán, 2004). Even if these local suppliers account for a significant share of production in a given cluster, other local, often medium-sized, producers may be integrated in relational value chains where family-based friendships between the buyer and supplier have developed across generations. In such chains, it is possible that mutual dependence and trust relationships may play a more significant role in determining which values and norms should guide ethical production (Lim and Phillips, 2008). At the other end of the scale, small and micro-enterprise cluster-based producers may be integrated into the world economy through arms-length transactions, selling their products abroad via agents or trading houses to less CSR-sensitive small-scale buyers in the North or Third World markets. In such situations, the scope for GVC governance in determining the 'ethical' values and norms that should guide production would be far less pronounced (Jiang, 2009). Second, the international buyers are rarely in a position to force their suppliers into full compliance with their codes of conduct. Audits - whether internal or external - undertaken by or at the request of international brands are often pre-announced, making it possible for suppliers to appear to be in compliance on the day of the audit by forging documents related to work hours and wages as well coaching their workers to provide the 'right' answers. They may then to return to 'business as usual' once the auditors leave (Barrientos, 2008; Harney, 2008). Finally, as many suppliers are facing multiple audits every year, they are often met with contradictory demands from their international customers and required to shoulder the costs of many of these audits that are undertaken at the request of their buyers. This experience tends to point towards the need for greater buyer coordination amongst the multiple codes and audits that suppliers are required to meet (Bolwig et al., 2010; Nadvi, 2008; Riisgaard et al., 2010). ${ }^{4}$

It is against this background that there may be greater scope for local cluster governance in assuming responsibility for the implementation of industrywide CSR approaches. Recent contributions to the cluster literature have demonstrated the potential of cluster-based initiatives in addressing poverty reduction goals (Nadvi and Barrientos, 2004). Similarly, cluster-based institutions of collective action such as business associations, chambers of commerce and other trade bodies - are said to provide effective platforms for organizing collective responses to common challenges (Nadvi, 1999b; see the collection of papers in Schmitz and Nadvi, 1999). In this regard, there may be a role for such local cluster institutions in the development of multi-stakeholder initiatives (MSIs) aimed at promoting CSR in developing countries.

The MSIs are different from individual private company standards (which are monitored by only one firm) and collective private company standards (which include more than a single company and are developed through a process of consensus building amongst industry actors). The distinction between collective private company standards and MSIs is that the latter involve a wider set of actors in the formulation, implementation and monitoring of social and environmental standards such as NGOs, trade unions, and sometimes national governments and/or international organizations (Tallontire, 2007). Southern-based MSIs embody a potential for facilitating access to high value markets, localizing standards, opening space for the intended beneficiaries to have their voice heard, establishing more independent forms of CSR monitoring and securing greater local buy-in or ownership of the social priorities embodied within such initiatives (Dolan and Opondo, 2005; Tallontire and Greenhalgh, 2005).

In spite of these achievements, there is still a need for developing a clearer understanding of the interaction of GVC and local cluster forces in determining which values and norms are to prevail in cluster-wide CSR interventions. A potentially promising contribution to this debate is Neilson and Pritchard's recent book Value Chain Struggles (Neilson and Pritchard, 2009). They argue that new forms of value chain governance and local institutional environments interact in ways that create various kinds of conflicts and tensions. In fact, the interaction between GVC governance and local forms of institutional governance is characterized by processes of struggle. From this point of view, GVC governance and local institutions are necessarily co-produced. That is, it is not only lead firms that determine the types of governance embodied with a given GVC 
but local institutions also play a significant role in co-determining what type of value chain governance prevails. The chain is both structured from the topdown by globally branded firms and simultaneously from the bottom-up by local, place-based institutions. Hence, there is no pre-determined outcome of these struggles in economic, social or environmental terms. Instead they must be analysed within the specific global and local spatial configurations in which these contending forces interact with a view to understanding how particular outcomes in terms of upgrading, labour and livelihood, environmental governance and the access that small-scale producers have to global and local markets are produced (ibid.).

In terms of the role that GVC governance plays in determining which norms and value are to prevail in cluster-wide CSR interventions, it is important to note that internationally branded buyers need to navigate between the CSR demands of their domestic audiences, such as consumers, NGOs and the media, and the perceived (ir)relevance and (lack of) applicability of these demands from the viewpoint of suppliers, workers and communities in the developing world (Lund-Thomsen, 2008). At one end of the scale, internationally branded buyers may choose to deal with these competing demands by adopting a global ethical strategy, employing universal moral standards that are to be exported through their CSR and human resource management practices to their suppliers in the developing world. Adopting a global ethical strategy may be particularly useful in demonstrating to home country constituencies that outsourcing of production to developing countries will not create a race-to-thebottom where brands' switch orders between countries in search of ever cheaper labour (Kolk and Tulder, 2004). In this strategy, serious instances of non-compliance with universal CSR requirements, e.g. the eradication of child labour, may thus be punished through sanctions such as brands severing their ties with non-compliant suppliers (LundThomsen, 2008).

At the other end of the scale, brands may adopt a multi-dimensional ethical strategy that takes a more relativist view of ethical challenges arising in their global supply chains. In this strategy, lead firms may adopt a more context-sensitive, situation-specific and tailor-made approach to dealing with CSR challenges in their supply chains. A multi-dimen- sional ethical strategy to CSR implementation may reflect the concern of some internationally branded buyers that swiftly adopting punitive measures for non-compliant suppliers may do more harm than good by forcing children to seek work opportunities in even more hazardous industries. Instead, the presence of child labour in developing countries is seen as a complex problem in this strategy, which needs a solution that does not leave the child worse off (Kolk and Tulder, 2004). ${ }^{5}$

In between the two extremes of the universal and the multi-dimensional ethical strategy lies a middle ground in which brands may commit themselves to adopting universal moral standards, e.g. the eradication of child labour, but choose to use different means to implement this principle in different contexts (Kolk and Tulder, 2002). For example, it may be possible to uphold the universal principle of ensuring a minimum age for a working child but leave it to the national legislations of different developing countries to determine whether the minimum ages should be 12,14 or 16 years. Similarly, it is possible to uphold on a universal ban on child labour involving children below the age of 12 but allow some forms of child work - here defined as light work undertaken from the age of 12 provided that this does not negatively affect the health and development of children or interfere with their education (Lund-Thomsen and Nadvi, 2009).

The issue of child labour points to the fact that it is not only GVC governance but also local governance forces that play key roles in determining the norms and values that guide joint action CSR initiatives within clusters. Cluster-based actors including industry associations, local NGOs, and other actors may challenge the idea that child labour is in itself a 'problem' that needs to be eradicated. In their studies of child labour in Bangladesh, Haider (2008) and Ruwanpura and Roncolato (2006) have challenged what they perceive as the uncritical application of concepts such as 'child labour eradication' to contexts in which extreme material depravation is widespread. In fact, simply focusing on preventing children from participating in any kind of work may not only disregard the economic rights of families and communities to work and earn a living, but also deny them any sense of agency in improving their own circumstances. Hence, in the viewpoints of these authors, the dominant understanding of child 
labour in developed countries may largely be incompatible with the real-life situations of working children in some parts of the developing world. Instead they suggest that it is necessary to study both the ongoing struggles of working children and their families within their respective contexts as well as the broader political economy in which they are embedded with a view to devising more locally appropriate solutions to their particular challenges.

Drawing on Nielson and Pritchards' (2009) study, we can thus see that the interplay between GVC and local cluster governance is not only a question of whether value chain or cluster-based actors are better positioned to ensure compliance with international CSR standards. In fact, the interaction between GVC governance and local cluster governance is likely to embody struggles over the particular values and norms that should guide CSR cluster-wide interventions. The outcomes of such struggles are not pre-determined but must be analysed within particular contexts where the interaction between GVC pressures and local cluster responses necessarily co-produce the outcomes of collective action CSR responses. In this article, we investigate how these competing forces are played out in the Sialkot and Jalandhar football clusters. The next section describes the similarities in and differences between the internal organization and external value chain linkages of the Sialkot and Jalandhar clusters, as well as their common CSR challenges.

\section{The Sialkot and Jalandhar football clusters}

Since 2000, China has emerged as the leading global exporter of inflatable footballs, but its dominance is mainly restricted to machine-stitched, low-end promotional and toy balls. In the area of hand-stitched balls, the traditional form of manufacturing footballs, South Asia is dominant with production concentrated in two clusters: Sialkot, Pakistan; and Jalandhar, India. But these are far from equal clusters. Sialkot is approximately three times bigger than the Jalandhar cluster in terms of numbers of firms (approximately 400 firms in Sialkot vs. 150 in Jalandhar); and eight times larger in terms of value of exports (US\$ 185 million vs. US $\$ 22$ million in 2005).

The Sialkot cluster has enjoyed a unique position as the leading source for premium hand-stitched match balls to the world's leading brands such as Nike and Adidas. Recent technological developments, however, have seen thermo-moulded balls emerge as a serious challenge to hand-stitched balls in the premium quality market, while improvements in machine-stitched products raise new competitive pressures for medium quality hand-stitched ball producers. The Jalandhar cluster does supply some leading regional brands (such as Mitre), but its output is primarily of lower-end promotional balls sold to medium/small sports brands or wholesalers/chain stores throughout the world. Both clusters face a number of common challenges. These include competition from Chinese producers using newer, machine-stitched technology as opposed to the 'older' hand-stitched production of soccer balls made in Sialkot and Jalandhar. Both clusters lack supporting industries supplying the key raw materials, such as PU and PVC, adding to their lead time to deliver in comparison with Chinese competitors. In addition, political instability has impacted on both clusters, and is currently a serious impediment to the Pakistani cluster.

While producers in both clusters gain from agglomeration advantages, the experience with local joint action across the two clusters is markedly different. The Sialkot cluster has a strong tradition, dating back at least two decades, of collective industry action to confront common challenges and respond to external threats. This history of local collective action has strengthened some of the institutions of local governance within the cluster, especially the respective trade bodies and the local chamber of commerce (SCCI). In contrast, joint action was relatively limited in the Jalandhar cluster until the end of the 1990s.

Most of the larger firms in the Sialkot cluster act as original equipment manufacturers (OEMs) to leading global brands. For the major brands, especially the two 'mega' brands Nike and Adidas, the GVC relationship is such that local suppliers are in a captive governance arrangement with their lead firms. Producing for such leading brands has its advantages - most notably in terms of production volumes, market access, and flows of technical knowledge and know-how. However, captive chain ties can leave local OEM suppliers highly vulnerable to the changing sourcing patters of global brands. An overview of the differences between the Sialkot and Jalandhar clusters are presented in Table I. 
Clusters, Chains and Compliance

TABLE I

Key Differences Between the Sialkot and Jalandhar Clusters

\begin{tabular}{lll}
\hline Characteristics/location & \multicolumn{1}{c}{ Sialkot } & \multicolumn{1}{c}{ Jalandhar } \\
\hline Number of firms & 20 (large) & 10 (medium) \\
& 50 (medium) & 140 (small and micro) \\
Number of subcontractors & 400 (small and micro) & 1000 \\
Number of football stitchers & 2400 & 12,000 \\
Exports (2005) & 30,000 & $\$ 22 \mathrm{~m}$ \\
Type of handstitched ball & $\$ 185 \mathrm{~m}$ & Medium-quality training ball \\
& High-quality match ball & Low-quality promotional ball \\
Key buyers & Medium-quality training ball & Medium-sized, smaller brands \\
History of collective action & Low-quality promotional ball & Limited \\
\hline
\end{tabular}

One of the main challenges posed by the leading brands is associated with compliance with their codes of conduct, especially with respect to labour standards. During the mid-1990s, producers in both the Sialkot and Jalandhar clusters faced international media allegations on child labour in their respective clusters (Khan, 2007; Nadvi, 2004, 2008). Although it is hard to verify, varying estimates suggested between 5000 and 17,000 child workers in the Sialkot football cluster (Husselbee, 2000) and according to an Indian government report, up to 12,000 in Jalandhar (Lund-Thomsen and Nadvi, 2009). In response to these allegations, and to avoid an international boycott of football exports, the Atlanta Agreement (AA) was formulated. Signed in Atlanta, Georgia, USA in February 1997, the AA was intended specifically for the Sialkot cluster, and involved negotiations between a wide range of stakeholders, including major sports brands, the World Federation of the Sporting Goods Industry (WFSGI), the Soccer Industry Council of America, the ILO, the United Nations Children Fund (UNICEF), Save the Children - UK (SCF) and the Sialkot Chamber of Commerce and Industry (SCCI). The AA proposed two main activities. First, a cluster-wide child-monitoring mechanism established to identify children involved in football stitching. Second, a social protection programme was developed so that the child stitchers could be transferred from stitching to school while ensuring that they and their families did not suffer in the process. Child labour monitoring was undertaken by the ILO through its International Programme for the Elimination of Child Labour (IPEC), and the social protection agenda was led by UNICEF and SCF. Much of the funding for the implementation of the AA came from international donors - most notably the United States' Department of Labor, and the Department for International Development (DFID) in the UK. The world football federation (FIFA) provided some financial support, while local producers in Sialkot also contributed to the implementation of the programme through the SCCI.

The Jalandhar cluster did not play any role in the framing of the AA. Nevertheless, faced with similar challenges, the Jalandhar cluster through its representative trade body, and with the support of the Government of India and FIFA, adopted the AA framework as a blueprint for implementing a similar intervention in Jalandhar. In contrast to Sialkot, however, monitoring was initially undertaken by the Swiss auditing and accreditation firm SGS, and there was only limited involvement of international agencies, donors and NGOs.

Trading with the Sialkot and Jalandhar clusters represents a significant reputational risk to international brands if child labour is found in their supply chains. Thus, in late 2006, Nike decided to sever ties with the largest supplier firm (and Nike's then sole supplier), Saga Sports, Sialkot, on the basis of alleged worker rights violations and unauthorized outsourcing of football stitching to home-based locations. Nike's 'pull-out' illustrates the extent to which large brands will go to avoid risks of being associated 
with child labour. Nike only re-entered the Sialkot cluster in late 2007, sourcing from new suppliers, and ensuring that through radical changes in production arrangements, its CSR requirements, especially to mitigate against the risks of being tainted by child labour, were adequately addressed. ${ }^{6}$

\section{Global value chain governance and CSR}

In this section, we explore how GVC governance pressures aimed at ensuring compliance with CSR standards have altered the forms of production organization in both the Sialkot and Jalandhar clusters. Initially, the AA led to the emergence of registered stitching centres linked to individual exporting firms in both Sialkot and Jalandhar. In terms of GVC governance, some brands and local suppliers in Sialkot went further, developing other models of production organization in response to CSR pressures. These included what we label as the 'home-grown CSR' model, the 'fair trade' model and the 'formal factory model' of production. The last one arose as a result of the 'pull-out' of Nike from Sialkot in 2006 and its subsequent return to sourcing from the cluster in 2007 . We briefly outline these distinct models below.

\section{The stitching centre model}

The emergence of the stitching centre model of production, in response to the child labour challenges and the formulation of the AA, is most clearly apparent in Sialkot. It has rapidly become the dominant mode of production organization in Sialkot. Each individual registered stitching centre is linked with an exporting firm. The stitching centres are either owned by the firm, or are sub-contractors to the exporting firm. Stitching centres vary in size, with as few as five persons in them, to a handful of centres with over 500 stitchers. By 2008, the average number of stitchers working in a stitching centre was 11 in Sialkot compared with only four stitchers per stitching unit in Jalandhar, reflecting the trend towards gathering the football stitching process into relatively larger units in Sialkot. ${ }^{7}$ As in home-based stitching, workers in the stitching centres continued to be paid on a piece-rated basis, and not on a waged contract. Besides, as they are contract workers, they do not have access to the legal benefits associated with Pakistan's labour laws. The centres do, however, provide a space for workers to congregate, and a number of women-only centres catering to women workers, some with additional support for women through childcare arrangements. Most critically, the stitching centres provide an effective mechanism to monitor labour and guard against child labour. Access to children is restricted, and working conditions more easily audited. Stitching centres can also be seen as a way to improve quality and product standardization through improved monitoring of stitching activities. In Sialkot, exporting firms, often under pressure from their lead buyers, agreed to join the ILO's independent and external child labour monitoring programme. Through this programme, ILO monitors conducted unannounced random visits to all the registered stitching centres to check on the presence of child workers. For many global buyers, the primary CSR demand was the need to ensure that no child was engaged in production. This system of child labour monitoring, underscored by the presence of ILO monitors, was seen as an adequate basis for ensuring this minimal CSR compliance.

Our interviews with key informants and our field visits suggested that the stitching centre model is far more widespread in Sialkot than in Jalandhar. A handful of medium-sized exporters from Jalandhar have established stitching centres, usually encompassing between 10 and 50 stitchers, to meet the compliance demands of their international buyers. To a large extent, however, home-based stitching continues to be the dominant form of production in Jalandhar, although most home-based units in Jalandhar are registered with the SGFI, the internal child labour monitoring body in Jalandhar.

For a small handful of brands sourcing from Sialkot, however, their CSR concerns go beyond child labour. Some brands - especially Nike and Adidas - emphasize compliance with their full code of conduct which incorporate a wider set of labour standards and labour rights. In one instance, in Sialkot, CSR concerns related to social developmental concerns which involved a European brand working with its supplier on addressing core community needs that were identified from the bottomup by the local supplier. Finally, a very few buyers 
have adopted a CSR value of 'fair trade' into their sourcing arrangements from local suppliers. However, to date it is only in Sialkot, and not in Jalandhar, that the home-grown and the fair trade models have emerged, and even these are limited in terms of scale. We outline these two variants below.

\section{The home-grown CSR model}

The home-grown CSR model is primarily characterized by relational value chain governance that exists between a European brand and its supplier in Sialkot. In this model, the CSR aspect of chain governance does not primarily take place through the implementation of codes of conduct or labour standards but instead through a social investment project. Although workers in this model continue to be paid on a piece-rate, and do not have the full legal benefits under labour law (such as formal social security, pension fund or bonus payments), they are, however, provided with a range of social support. This is aimed at improving their welfare and reducing worker turnover rates for the supplier. The costs of social provisioning within this model are equally borne by the European brand and the Sialkot supplier, and, uniquely, the local supplier is fully in charge of designing and implementing the programme which is why we call it the 'home-grown' model.

The home-grown CSR model arose from a house-to-house survey in some of the villages that had a concentration of stitchers who were mainly stitching for the Sialkot supplier to the European brand. According to the survey, stitchers reported taking advance payments from subcontractors, as income generated from stitching footballs was not sufficient to cover medical emergencies, or pay for children's school fees, books and uniforms. As a result, many stitchers had accumulated significant amounts of debt. As their main social priorities, the stitchers identified financial assistance to pay educational and medical expenditures, followed by repair work at home, dowry for the girls, toilets, a pump, fans, electricity meter and other household durables. A social protection programme was developed for the stitchers of the European brand/the Sialkot supplier on the basis of the survey findings. This programme included the provision of a subsidy to enable parents to pay their children's school fees, the provision of informal education to children aged 8-14 - either at a company-owned learning centre or through the use of mobile teachers visiting the children in their homes, an adult literacy programme, as well as provision of medicine and free-of-cost health treatment. The latter is done through agreements with local doctors and hospitals that are reimbursed by the project once patients have availed treatment.

\section{The fair trade model}

The fair trade model of chain and production organization is also characterized by relational chain governance ties between a small fair trade brand that has carved out a niche for itself in the European market and its local supplier in Sialkot. In this model, the CSR aspect of chain governance takes place through standards for fair trade footballs. A special feature is that a higher premium is paid for each ball stitched, which, in theory, secures a higher return to workers, while $20 \%$ of the fair trade premium is to be invested in community development projects that benefit in-house workers and the stitchers working in the centres of the company outside factory premises. Decisions on allocations of this premium are made by a separate NGO with representatives from both management and workers. However, fair trade accounts for a small share of production, not only in the Sialkot cluster but also with this specific supplier. Less than $10 \%$ of the Sialkot 'fair trade' supplier's production of footballs is done under the fair trade arrangement given the prevailing limited international demand for fair trade footballs.

The fair trade model was designed through a detailed assessment of what constituted a fair living wage for a football stitcher in Pakistan. The outcome of this assessment was that a fair living wage would be PKR 6000 per month. This would ensure that all basic necessities were covered while some funds could still be saved. This was used to calculate what fair stitching wages would be. Fair stitching wages were determined to be more than PKR 4000 per month, assuming that orders are constantly available. Two workers per stitching family would be required per month to reach the fair trade minimum. 
The formal factory model

In sharp contrast to the models of production arrangement described above, where stitching, the most labour-intensive task in football manufacture, is undertaken by contract workers in designated stitching centres located across a wide area in Sialkot and its environs, a new mode of production arrangement is emerging. The formal factory model describes the relationship between Nike and Silverstar, its main supplier in Sialkot since 2007. This is marked by captive chain governance between Nike and its OEM supplier. The critical difference in contrast to other leading brands is that Nike requires that all production-related work is undertaken in-house, within the factory's premises. Moreover, all the workers have to be waged permanent (as opposed to contract) employees. This gives, in principle, access to a set of labour rights under national labour laws including social security, health insurance and employee old-age benefits. The piecerate system is abolished and replaced by a fixed rate system with added bonus incentives for higher productivity. Moreover, in the formal factory model, ILO Conventions 87 and 98 should be fully abided by the factory to secure freedom of association and collective bargaining. These rights of workers are to be established through workermanagement dialogue on workers' conditions and worker grievances. There has to be extensive internal and independent third-party monitoring of compliance and production. In addition to internal and third party monitors, Nike's agent in Pakistan, Matrix Sourcing, have the responsibility for CSR monitoring in Silverstar. Finally, a human resource management computer-aided tracking system makes it possible to trace exactly which worker stitched a specific Nike football, the date and time that work was done, the remuneration to that worker as well as details on the worker's background, age and overall wage and other benefits.

In Table II below, we summarize how the restructuring of GVC ties in the Sialkot and Jalandhar football clusters has led to the variety of CSR-driven production models introduced in both clusters.

As seen in Table II, the most significant difference between the Sialkot and the Jalandhar football clusters in terms of GVC ties is that some suppliers in the Sialkot cluster are linked into chains with the mega-brands, Nike and Adidas, whereas the top-tier buyers in Jalandhar include medium-sized to smaller brands, such as the UK-based Pentland Group (the Mitre brand), or French brand Decathlon. Obviously, both clusters also partly share similar GVC ties. From medium-sized to smaller sports brands and to non-branded sports buyers source footballs in both Sialkot and Jalandhar. Similarly, there are a number of East European and Third World buyers both traditional sports and non-sports buyers which source training and promotional balls from the two clusters. However, the presence of Nike and Adidas in Sialkot and their absence in Jalandhar is significant to the extent that these global brands account for approximately $60 \%$ of world sales of footballs and are closely monitored by advocacy groups around the world. As such, they cannot afford to have their brands associated with child labour, and their CSR enforcement and monitoring procedures are relatively stricter in Sialkot than those

TABLE II

Global value chain governance and CSR in Sialkot and Jalandhar

\begin{tabular}{lll}
\hline Industrial cluster & \multicolumn{1}{c}{ Sialkot } & \multicolumn{1}{c}{ Jalandhar } \\
\hline Top-tier buyers & Mega-brands (Nike/Adidas) & Medium-sized/smaller sports brands \\
Main product & Match balls & Promotional balls \\
Restructuring of GVC ties & Extensive & Limited \\
Dominant form of football stitching & Centre-based work & Home-based Work \\
Other CSR based models of production & Home-grown CSR model & None \\
& Fair trade model & \\
& Formal factory model & \\
&
\end{tabular}




\section{Clusters, Chains and Compliance}

faced by the top-tier Jalandhar producers. Added to this, Sialkot mostly specializes in the production of top-end matchballs that are used by national teams and by national and regional football leagues, media attention and individual sponsorship contracts of which are worth millions of dollars. This contrasts with the sale of promotional balls from Jalandhar, which are not used in high profile, media-attractive, professional matches.

The presence of these global brands in Sialkot is significant in explaining how the cluster has moved away from home-production towards a stitchingcentre based model of producing footballs. However, while football stitching is mostly done inside football centres in Sialkot today, this does not imply that all home-based stitching of footballs has been entirely eliminated within the cluster. While no official numbers on the extent of home-based football stitching in Sialkot exist, there is still a domestic market for promotional and training footballs in Pakistan, some third-world buyers, and non-sport, less CSR-sensitive buyers in Europe and North America, which source footballs from local suppliers that are not members of the AA. Nevertheless, an important difference between the Sialkot and Jalandhar clusters is that home-based stitching continues to be the dominant mode of production organization in Jalandhar. While a limited number of stitching centres have been established by a few Jalandhar's top-tier suppliers, even these top-tier suppliers have a substantial part of their balls stitched in home-based locations. In terms of the relationship between GVC governance and CSR within the cluster, this means that it is relatively more difficult in the Jalandhar cluster to monitor against child labour than in Sialkot.

Finally, in terms of the spread of buyer-supplier CSR models within both clusters, Sialkot has witnessed more experimentation with other models of production organization than Jalandhar. While individual suppliers are engaged in philanthropic projects in Jalandhar (such as company-run hospitals and the provision of student scholarships), these reflect the individual commitment of entrepreneurs to CSR in Jalandhar, and not external CSR pressure. While similar acts of philanthropy are also undertaken by individual entrepreneurs in Sialkot, the emergence of some new CSR models in the cluster can directly be related back to both different types of value chain governance and also competing norms/values in terms of what constitutes appropriate forms of work and desired social benefits linked to football stitching.

In Sialkot, the formal factory model is linked to Nike's preference for factory-type production where quality and work conditions are easier to control. Here the local supplier is linked into a captive chain with Nike where the latter largely dictates what is to be produced, how, when, at what price and under what work conditions. The fair trade model, however, is based on an alternative vision where the local supplier is linked into a relational chain with Northern buyers where stitching takes place according to the stitching centre model. Here, the main focus is on institutionalizing an alternative form of trade that mainly benefits the stitchers in terms of securing an above market rate price per football while empowering football stitchers through the establishing of joint decision-making bodies that decide how part of the price-premium for fair trade footballs should be distributed. Finally, the 'homegrown' CSR model is based on an approach that is grounded in a bottom-up view of how the GVC should be structured. While recognizing the need to comply with external CSR demands of buyers following the stitching centre model, the buyer has handed over responsibility for CSR implementation to its local supplier. The CSR approach is based upon an on-site identification of needs of stitchers and their households. Educational and health security benefits were amongst the top issues prioritized by such stitchers. This contrasts with Nike's objectives that labour rights are addressed through implementing full legal labour and social benefits in the formal factory model.

\section{Local cluster governance and CSR}

The previous section has shown how GVC governance pressures, specifically with respect to child labour, led to changes in patterns of production arrangements in both clusters. This is especially pronounced in Sialkot from where the leading global brands source premium hand-stitched footballs. We now turn to the role of local cluster governance, and its importance in addressing external CSR concerns, specifically implementing the AA and developing effective child labour monitoring mechanisms. 
Local cluster governance played an important part in both clusters in response to the initial challenge on child labour. The Sialkot Chamber of Commerce and Industry (SCCI), the leading trade body in the Sialkot cluster, took the lead in co-ordinating the cluster's response, mobilizing support from the central government and taking an active part in the formulation of the AA. The SCCI was one of the core signatories to the AA and undertook to co-finance $23 \%$ of the total costs associated with implementing the ILO-IPEC's child labour monitoring mechanism. ${ }^{8}$ This sum, of US $\$ 221,700$, was raised by SCCI through a levy on its football manufacturing member firms who joined the ILO-IPEC monitoring system. While the actual implementation of the monitoring and social protection components of the AA were undertaken by external actors, SCCI continued to be a co-ordinating actor for the local industry, liaising with the AA programme implementation team as the representative body for local industry (Lund-Thomsen and Nadvi, 2009). While the SCCI represented all manufacturing industries in Sialkot, football producers as the leading exporters from the region played a central if not dominant role in the workings of the chamber. Furthermore, the issue of child labour was recognized as a challenge for all of Sialkot's export-oriented small firm clusters. These diverse clusters had already, through the SCCI, collaborated on a number of cross-cluster joint action initiatives. This included the setting up and financing of a dry port in Sialkot in the early 1990s - the first of its kind in Pakistan, to facilitate export procedures and reduce transport and storage costs for local producers. More recently, the SCCI spearheaded the campaign and funding for the establishment of Sialkot's international airport again the first such undertaking by the private sector in Pakistan.

The relatively smaller cluster of Jalandhar also had a representative cluster trade body, the Sports Goods Manufacturers and Exporters Association (SGMEA). However, the Jalandhar sports good sector was more sharply divided than Sialkot between separate producers engaged in the manufacture of footballs, cricket bats and equipment, and other sports goods. The divergent interests of these manufacturers led to a fragmented view within the cluster in terms of how to respond to the allegations of child labour. In order to articulate a more effective collective response to this challenge, the cluster's 25 leading football manufacturers formed the Sports Good Federation of India (SGFI) in 1999 as a non-profit entity devoted to the prevention and rehabilitation of child labour in the Jalandhar cluster. SGFI then negotiated with the World Federation of Sports Goods Industry (WFSGI), ILO and SCF to implement a similar monitoring and social protection programme as that developed in Sialkot for the Jalandhar cluster. Although the international actors were ready to undertake this agenda - with funding from the US Department of Labor - the government of India intervened to stop external monitoring by the ILO. With funding from FIFA, SGFI then obtained the services of SGS to carry out the monitoring system as the external third party monitors. Unlike the much larger social protection programme in Sialkot, which was in excess of US\$ 2 million over the period 1997-2004 and funded almost solely by donors, the social protection component of the programme in Jalandhar was smaller in scale (US\$ 208,000 from 2004 to 2006) and financed entirely by local producers through the SGFI (Lund-Thomsen and Nadvi, 2009).

Local cluster institutions were key to the development of collective responses in both clusters, articulating the collective interests of local suppliers, negotiating on behalf of the cluster and providing significant financial contributions towards the implementation of the child labour monitoring and social protection agenda. We now turn to a more detailed analysis of how the local monitoring system evolved, and its implications for local cluster governance.

Two types of monitoring were conducted in both clusters: internal monitoring by the manufacturers, and external monitoring by independent third parties. Independent monitoring was through the ILOIPEC programme in Sialkot during the period 1997-2003 and in Jalandhar by Swiss firm SGS from 1999 to 2003. After 2003, when donor funding for external monitoring initiatives came to an end, local institutions took over the monitoring functions. An independent 'not-for-profit' NGO was formed in Sialkot to address ILO-IPEC's monitoring tasks. This organization, the Independent Association for Monitoring and Child Labour (IMAC), incorporated most of the ILO-IPEC local monitoring staff, assets, and monitoring procedures. In Jalandhar, 
SGFI took over from SGS to provide child labour monitoring for its member firms.

The child labour monitoring mechanisms in both clusters continue to function along similar lines to those initially developed under the AA. However, as Table III shows, there are a number of differences between the monitoring mechanisms in Sialkot and Jalandhar. These raise questions about the relative capacity of both IMAC and SGFI to monitor child labour in their respective clusters, and more broadly about the dynamics of local cluster governance.

There are important differences between the institutional frameworks of the two industrial clusters for child labour monitoring. First, IMAC has a larger membership in Sialkot than SGFI has in Jalandhar. In part, this is a reflection of the relative scale of the Sialkot cluster vis-à-vis the Jalandhar cluster. Second, IMAC's board includes a diverse body of stakeholders, from local industry, international organizations, government agencies, academia to civil society organizations. In contrast, SGFI's board is entirely dominated by manufacturers from the Jalandhar football cluster. The presence of diverse stakeholders implies that IMAC needs to balance the interests of different groups within the cluster. In contrast, SGFI being dominated by the industry allows it to respond more quickly to industry concerns. However, the fact that it is not institutionally independent from industry can lead to doubts on the reliability and quality of the information that it provides about its monitoring and social protection activities. Third, football stitching in Jalandhar remains predominantly a home-based activity. Hence, SGFI has to monitor more units than IMAC; yet it has less than half the manpower to undertake this task. Fourth, whereas IMAC updates its database of stitching centres, contractors and stitchers every month, the database of the SGFI has not been updated on a regular basis after the end of the last decade. Hence, 'old' locations where footballs used to be stitched continue to be registered as locations in the SGFI database whereas new locations are not continuously updated, making it more difficult to track and monitor all the stitching locations. Finally, there is greater public access to information about IMAC's monitoring procedures and performance than the access to similar information on SGFI's monitoring activities. Interested parties can find detailed explanation of IMAC's functions, monthly monitoring updates, and the presence of children found stitching (see http://www.imacpak.org). In contrast, on the SGFI Website (http://www.sgfi. org), there is a lack of detailed information on its child monitoring system or the progress achieved to date.

In sum, although local cluster governance does matter, especially in articulating each clusters' response to the child labour challenge, the nature of monitoring in the two clusters raise doubts on the strength and effectiveness of local governance. The Jalandhar example, in spite of being a collective industry monitoring model, does not have the same degree of independence, and thus, it potentially lacks the same degree of credibility, as that observed in Sialkot. This is further underlined by the differing levels of staffing provided for monitoring in each cluster.

TABLE III

Child labour monitoring: the Sialkot and Jalandhar clusters compared

\begin{tabular}{lll}
\hline Post 2003 child labour monitoring & \multicolumn{1}{c}{ Sialkot } & Jalandhar \\
\hline Local monitoring institution & IMAC & SGFI \\
Governance structure & Multi-stakeholder board & Industry-based \\
Members & 88 & 30 \\
Number of stitching locations monitored & 2655 Units & 3300 Units \\
Number of monitors & 12 & 5 \\
Frequency of monitoring & 6 Weeks & 13 Weeks \\
Database maintenance & Extensive & Limited \\
Public information access & High & Low \\
\hline
\end{tabular}


GVC governance or local cluster governance - which one dominates the CSR response in the Sialkot and Jalandhar clusters?

The interaction between GVC governance and local cluster governance has resulted in different approaches to institutionalizing compliance in the Sialkot and Jalandhar football clusters. In Sialkot, CSR demands of international buyers, the threat of boycotts and sustained scrutiny from international media and advocacy NGOs were instrumental in bringing about a transition from home-based to centre-based stitching of footballs. In addition, new practices related to fair trade, which we call 'homegrown CSR' and factory-based production, emerged in response to CSR pressures. In Jalandhar, where the cluster's main buyers tend to be less-dominant brands, CSR compliance did not imply a radical restructuring of production arrangements. At the same time, GVC pressures and the presence of a tradition for collective action in Sialkot in areas prioritized by the local entrepreneurs appear to facilitate the development of a potentially stronger cluster-wide child labour monitoring mechanism in Sialkot than in Jalandhar.

At the outset, we asked the respondents if vertical chain governance or horizontal cluster governance determined the nature and effectiveness of the cluster responses to CSR demands on child labour. Our study indicates that both the GVC ties and local cluster institutions played a part. Horizontal cluster governance was central to the ability of local producers to organize collective action and implement the framework of the AA. Such forms of local horizontal governance continue to be important with regard to the ways in which local monitoring mechanisms have evolved in the two clusters. At the same time, vertical chain governance especially where leading brands have captive governance ties with their suppliers was critical in determining how production is organized in such ways that labour can be more easily monitored. This is more pronounced in the Sialkot cluster where home-based stitching has systematically given way to centre-based work. Moreover, Nike's adoption of an integrated factorybased model of production with permanent waged labour by its lead supplier suggests an attempt to use GVC ties to push further on CSR-related labour standards while reducing the risks to the brand of non-compliance by its suppliers.
There are, however, some important distinctions in the notion that both vertical and horizontal governance mattered. Horizontal governance appears to be more effective and pronounced, when vertical GVC pressures are sustained over time. At the outset of the child labour 'crisis', local cluster institutions - SCCI in Sialkot and SGFI in Jalandhar - played an important part in ensuring that a collective strategy was developed and that a commitment, certainly a financial commitment, was made in each cluster to address the child labour issue. Similarly, the 2006 pull-out of Nike from Saga Sports led IMAC to promote the use of larger stitching centres and publicize the number of children found in its members' stitching centres on a monthly basis. Shortly afterwards, in 2008, media reports about the continued use of child stitchers in the Jalandhar football industry prompted some of SGFI's producers to start the process of registering their stitching units again. Hence, the local child labour monitoring bodies in both clusters continue to provide a basis for collective action but in instances where local cluster governance dominates, which appears to be the case in Jalandhar, producers have fewer incentives to retain a relatively more independent and stronger monitoring mechanism as is the case in Sialkot. Hence, the nature of a cluster's GVC ties appear important in ensuring that local cluster-based institutions sustain strong collective CSR monitoring mechanisms over time.

Nevertheless, in some instances local cluster governance is replaced by GVC governance. For example, Adidas relies on its own sourcing and CSR office in Sialkot as well as third-party compliance inspectors to monitor its suppliers in Sialkot. At the same time, the fact that a leading brand such as Nike has opted for factory-based production where it can more effectively monitor against child labour suggests an on-going fear that the existing monitoring capabilities of IMAC in Sialkot do not provide sufficient insurance for Nike that its supply chain will be effectively monitored against child labour. Instead, Nike's decision to require that its new suppliers in Sialkot must shift their production arrangements to a factory context with permanentwaged employees suggests that for the leading brands vertical chain governance remains the dominant basis for ensuring compliance with their CSR norms. 
This question underlines what Neilson and Pritchard (2009) note that the outcome of the interplay between vertical chain governance and horizontal cluster governance is not necessarily predetermined. Rather it emerges out of a contextually specific struggle between these diverse pressures. Our study suggests that the CSR-related cluster development initiatives need to negotiate between the potentially conflicting needs of promoting local cluster governance and addressing global chain governance concerns. In this regard, we observed in both clusters a fundamental disagreement between some local exporters and international brands/advocacy organizations not only as to whether child labour constitutes a problem per se, but also about whether the developmental outcomes of eradicating child labour within the clusters are positive or negative for the local industry and its workers. According to some manufacturers that we interviewed, the 'imposition of the child labour issue' had not only increased the industry's cost structure, but also denied children the opportunity to learn the skill of stitching and forced many home-based women workers out of the workforce as a result of the introduction of the stitching centre system. Hence, while removal of children from their supply chains was necessary to avoid an international boycott, some manufacturers did not appear to believe that the implementation of the AA had either benefitted them or workers within the industry.

These 'local views' may reflect the broader trend where CSR compliance in GVCs is mostly perceived by both international brands and local exporters as a risk management tool that does not necessarily translate into improved economic returns to either local producers or workers. It raises the broader question of whether, and if so, how clusterwide CSR interventions can achieve a greater level of local embeddeness. To do so may imply moving beyond a risk management function towards securing more meaningful returns to local enterprises and workers within the cluster. The limited example of the 'home-grown' CSR model of organization may suggest a way forward building on existing philanthropic practices based on entrepreneurial paternalism. However, even in that model, as currently practised, workers are contract labourers with limited labour rights.

\section{Conclusion}

In this article, we have examined the relationship between GVC governance and local cluster governance in facilitating compliance with international CSR standards within the two leading soccer ball clusters of South Asia: Sialkot in Pakistan and Jalandhar in India. While there are a number of commonalities across the two clusters, most notably in terms of the CSR challenges on child labour, there are also some stark differences - especially with respect to scale, to types of lead buyers and dominant forms of production organization. Hence, the interplay between horizontal and vertical governance has been varied - over time, across the two clusters, and within each cluster resulting in quite distinct outcomes in terms of child labour monitoring practices as well as forms of work organization. Our analysis suggests that there is a role for both vertical chain and horizontal cluster governance approaches to addressing CSR monitoring within clusters. The relative strength of the cluster-based CSR-monitoring mechanisms in Sialkot and Jalandhar appear to depend upon the toughness of pressures from internationally branded buyers and the presence and/or absence of strong collective action institutions within these clusters, which can facilitate the implementation of such monitoring mechanisms.

A particularly interesting finding emerging from our study is that the dominant focus on eradicating child labour from the Sialkot and Jalandhar football clusters appears to have overshadowed other, and from a labour standards perspective, more significant consequences of the interplay between global governance and local governance attempts at facilitating CSR compliance within the clusters: the emergence of new forms of work organization and individual CSR models. True, the interplay between vertical and horizontal governance has played a key role in the attempts of both clusters to eradicate child labour from football manufacturing through the introduction of CSR, particularly child labour, monitoring mechanisms. However, it is not these CSR-monitoring mechanisms in their own right but rather the introduction of new work forms and CSR models within both clusters, which might affect the work conditions of football stitchers in Sialkot and Jalandhar.

This is a particular area that clearly deserves further analysis and research. We have little knowledge about 
the outcomes for stitching workers across the two clusters, and within each cluster in terms of the different models of work organization. While this constitutes a central part of our current research agenda, we are now able to develop a number of interlinked hypotheses about the links between participation in factory-based, centre-based, and home-based football stitching and the work conditions under which football stitchers labour in Sialkot and Jalandhar. First, on the basis of our on-going fieldwork in the Jalandhar and Sialkot clusters, we believe that stitchers may receive higher wages from participating in factory-based forms of football stitching than centre-based football stitching. In turn, those stitching footballs in centres are likely to receive higher wages than home-based football stitching. In other words, as we move from more formal work settings towards more informal work settings, the earnings that stitchers receive from football stitching will tend to decrease. Second, we hypothesize that we will experience a similar movement when it comes to the social protection afforded to football stitchers. In other words, stitchers engaged in factory-based football stitching are more likely to have health insurance, pension schemes, and receive unemployment benefits than centre-based stitchers, some of whom may receive some coverage through particular CSR models (the fair trade or home-grown models). However, in the informal economy, social protection is likely to be absent for the home-based football stitchers. Our third hypothesis is that the introduction of factory-based and centre-based forms of football stitching are likely to have particular gender implications. Due to the traditional division of labour that exists, particularly in Pakistani Punjab, men are often considered responsible for financially supporting their families while women are in charge of domestic household duties. Hence, we expect that the factorybased model of football stitching with its emphasis on a full-time, a 9-5 working day will favour the participation of men to a greater extent than women. Due to their greater proximity to the homes of football stitchers, we expect stitching centres with flexible work timings to have a more balanced participation of men and women. At the same time, we would expect home-based football stitching to be dominated by female stitchers as this might provide them with greater possibilities for combining domestic household duties such as child rearing with the possibility of earning a living. Hence, in terms of the ability of women to access paid work, the introduction of factory-based and centre-based forms of football stitching might have the unintended consequence of creating greater income inequalities between male and female football stitchers. Our fourth and final hypothesis is that the football stitchers are not just affected by the introduction of these new work forms, they might also consciously self-select in and out from participation in factory-based, centre-based, and home-based forms of stitching. In other words, it may not be directly possible to draw conclusions such as 'factory-based football stitchers will be better off than home-based stitchers because their earnings are likely to be significantly higher'. While the introduction of factory-based and centre-based forms of work do appear to restrict the access of female stitchers to paid work, both female and male stitchers may prefer lower earnings in cases where they also engage in other forms of paid work, have other family members generating sufficient income, or domestic duties such as child rearing that might prevent them from taking up a full-time $9-5$ job in the factory. Hence, the flexibility of work timings and the ability to manage their own work schedule may be more important to some home-based stitchers than generating a higher income.

\section{Notes}

1 Blowfeld and Frynas (2005, p. 503) describe CSR as a set of practices that reflect three distinct concerns for companies: first, their need to be aware and take responsibility for the impact of their activities on society; second, that companies need to be concerned about the actions and practices of those from whom they source, in particular their dispersed supply chains; and finally that companies 'need to manage their relationship with wider society'.

2 Debates on CSR and socially responsible business have focused on philanthropic measures by corporate actors, to an interest in viewing poor communities as critical customers at 'the bottom of the pyramid' (Frynas, 2008). There are also concerns, especially amongst sceptics, that CSR initiatives essentially seek to mitigate risks for global brands, providing a public relations fig leaf to hide dubious sourcing practices (Christian Aid, 2004; Jenkins, 2002).

3 In this context, it is worthwhile noting that collective action amongst industrialists has also been 


\section{Clusters, Chains and Compliance}

accounted for using the concept of 'collective institutional entrepreneurship'. Institutional entrepreneurship involves purposeful actors, employing their political and social skills to engineer change in a given context or issue area. To the extent that institutional entrepreneurship is highly complex and involves large numbers of widely dispersed actors, joint action based on mutual interests may become the way in which these actors overcome collective inaction with the view to transforming existing or creating new institutions (Wijen and Ansari, 2007). In this article, we consciously employ the term industrial clusters as the possibilities for local collective action that we are studying arise to a large degree out of the promixity of a large number of private and public actors within a confined geographical space. This is different from the idea of collective institutional entrepreneurship that envisages collaboration amongst a large number of widely dispersed actors.

4 In addition, the imposition of ethical guidelines in GVCs is often criticized for being a top-down approach as codes tend to be formulated in corporate headquarters in North America or Europe without any input from the intended beneficiaries - suppliers and workers in the developing world (De Neve, 2009). This means that issues prioritized in such codes tend to reflect the concerns of consumer, NGOs, and trade unions in the West, while the livelihood and social protection concerns of workers in export-oriented industries in the developing world are often overlooked (LundThomsen, 2008).

5 In a subsequent study, Tulder et al. (2009) have further developed the argument that the home country of multinational enterprises plays a role for the way in which these companies transmit CSR compliance pressures throughout their GVCs. In distinguishing between a liability and a responsibility approach to ethical supply chain management, Tulder et al. state that some buyers adopt a more inactive or reactive response to stakeholder demands for increased CSR compliance, resulting in confrontational forms of stakeholder interaction and/or evasion. In the responsibility approach, buyers adopt a more active or even pro-active approach that involves the broadening of the circle of actors involved in standard formulation and implementation, thus speeding up the process of change and facilitating greater compliance with CSR standards. In their study of the implementation of occupational health and safety requirements in the supply chains of leading branded firms in the United States, Europe, and Japan, Tulder et al. conclude that the European firms are more used to ensuring stakeholder involvement which helps them secure greater levels of compliance with their CSR standards. However, in our assessment, the distinction between a liability and a responsibility approach to ethical supply chain management may be more appropriate in industries that have recently been exposed to CSR demands. In the case of the football industry, internationally branded firms have been exposed to CSR compliance pressures for more than 15 years. Hence, many firms in this industry, particularly Nike and Adidas, have already adopted a pro-active approach to engaging their stakeholders. However, anecdotal evidence from our study suggests that sports brands based in the United States may be more prone to adopt a universal ethical strategy whereas European brands tend to use either a multi-dimensional strategy or situate themselves in the middle ground between universal and multi-dimensional approaches.

6 We have mapped the events surrounding Nike's pullout and subsequent re-entry into the Sialkot cluster in a previous publication (Lund-Thomsen and Nadvi, 2009). After its pull-out, Nike specified a number of CSR requirements for its re-entry (i.e. choice of a new Sialkotbased supplier), which we outline as the factory-based model in this article. However, as we also explain, the Nike pull-out did not succeed in producing any substantive effects in the transformation or creation of new cluster-based institutions to address a wider set of CSR-compliancebased issues within the cluster. Part of the reason might have been Nike's decision to re-enter Sialkot relatively soon after its pull-out, thus reducing the pressure on cluster-based actors to address the concerns raised by Nike.

7 It should be noted here that we are using the 'stitching centre' here to refer to a building with a roof in which stitching takes place. In IMAC's terminology, a stitching centre can refer to any location, whether inside or outside, where five or more stitchers gather together. In the case of female stitching centre, only three ladies are required to gather together before it can be called a stitching centre in IMAC's view (Dogar, 2004).

8 The remainder of the costs associated with the ILOIPEC programme were borne by the US Department of Labour through a grant to the ILO.

\section{Acknowledgments}

This article draws on a study commissioned by the United Nations Industrial Development Organisation (UNIDO), Vienna, and a study funded by the Danish Social Science Research Council. The authors are grateful for comments on earlier drafts from Michele Clara, Mukesh Gulhati, Stefano Ponte and by anonymous referees. The conclusions presented here do not reflect in any way on thinking within UNIDO and the authors are solely responsible for all errors. 


\section{References}

Accountability (w. United Nations Industrial Development Organisation (UNIDO): 2006, SME Clusters and Responsible Competitiveness in Developing Countries (Accountability, London).

Altenburg, T.: 2006, 'Governance Patterns in Value Chains and Their Developmental Impact', European Journal of Development Research 18(4), 498-521.

Altenburg, T. and J. Meyer-Stamer: 1999, 'How to Promote Clusters: Policy Experiences from Latin America', World Development 27(9), 1693-1714.

Bair, J. and G. Gereffi: 2001, 'Local Clusters in Global Chains: The Causes and Consequences of Export Dynamism in Torreon's Blue Jeans Industry', World Development 29(11), 1885-1903.

Barrientos, S.: 2008, 'Contract Labour: The 'Achilles Heel' of Corporate Codes in Commercial Value Chains', Development and Change 39(6), 977-990.

Barrientos, S. and S. Smith: 2007, 'Do Workers Benefit from Ethical Trade? Assessing Codes of Labour Practice in Global Production Systems', Third World Quarterly 28(4), 713-729.

Bazan, L. and L. Navas-Alemán: 2004, 'The Underground Revolution in the Sinos Valley: Upgrading in Global and National Value Chains', in H. Schmitz (ed.), Local Enterprises in the Global Economy: Issues of Governance and Upgrading (Edward Elgar, Cheltenham, UK), pp. 110-139.

Blowfeld, M. and J. F. Frynas: 2005, 'Setting New Agendas: Critical Perspectives on Corporate Social Responsibility in the Developing World', International Affairs 81(3), 499-513.

Bolwig, S., S. Ponte, A. du Toit, L. Riisgaard and N. Halberg: 2010, 'Integrating Poverty and Environmental Concerns into Value-Chain Analysis: A Conceptual Framework', Development Policy Review 28(2), 173-194.

Ceglie, G., M. Clara and M. Dini: 1999, 'Cluster and Network Development Projects in Developing Countries: Lessons Learned through the UNIDO Experience', in Organization for Economic Cooperation and Development (ed.), Boosting Innovation: The Cluster Approach (OECD, Paris), pp. 269-292.

Christian Aid: 2004, Behind the Mask - The Real Face of Corporate Social Responsibility (Christian Aid, London).

Coe, N. M., P. Dicken and M. Hess: 2008, 'Global Production Networks: Realizing the Potential', Journal of Economic Geography 8(3), 271-295.

De Neve, G.: 2009, 'Power, Inequality and Corporate Social Responsibility: The Politics of Compliance in the South Indian Garment Industry', Economic and Political Weekly 44(22), 63-71.
Dogar, N.: 2004, A Desk Study of the Sialkot Soccer Ball Project, Child and Social Development Organization (Sialkot Chamber of Commerce and Industry, Sialkot, Pakistan).

Dolan, C. S. and M. Opondo: 2005, 'Seeking Common Ground - Multi-Stakeholder Processes in Kenya's Cut Flower Industry', Journal of Corporate Citizenship 18, 87-98.

Ethical Trading Initiative (ETI): 2006, ETI Code of Labor Practice - Do Workers Really Benefit? (Institute of Development Studies, University of Sussex, Brighton, UK).

Fransen, L. and A. Kolk: 2007, 'Global Rule-Setting for Business: A Critical Analysis of Multi-Stakeholder Standards', Organization 14(5), 667-684.

Frynas, J. G.: 2008, 'Corporate Social Responsibility and International Development: A Critical Assessment', Corporate Governance: An International Review 16(4), 274-281.

Gereffi, G.: 1999, 'International Trade and Industrial Upgrading in the Apparel Commodity Chain', Journal of International Economics 48(1), 37-70.

Gereffi, G., T. Sturgeon and J. Humphrey: 2005, 'The Governance of Global Value Chains', Review of International Political Economy 12(1), 78-104.

Gibbon, P. and S. Ponte: 2005, Trading Down: Africa, Value Chains and the Global Economy (Temple University Press, Philadelphia, PA).

Haider, M.: 2008, 'Recognizing Complexity, Embracing Diversity: Working Children in Bangladesh', South Asia Research 28(1), 49-72.

Harney, A.: 2008, The China Price - The True Cost of Chinese Competitive Advantage (Penguin Press, New York, NY).

Humphrey, J. and H. Schmitz: 2002, 'How Does Insertion in Global Value Chains Affect Upgrading in Industrial Clusters', Regional Studies 36(9), 1017-1027.

Husselbee, D.: 2000, 'NGOs as Development Partners to the Corporates: Child Football Stitchers in Pakistan', Development in Practice 10(3-4), 377-389.

Jenkins, R.: 2002, 'Introduction', in R. Jenkins, R. Pearson and G. Seyfang (eds.), Corporate Responsibility and Labour Rights - Codes of Conduct in the Global Economy (Earthscan, London, UK), pp. 1-12.

Jiang, B.: 2009, 'Implementing Supplier Codes of Conduct in Global Supply Chains: Process Explanations from Theoretic and Empirical Perspectives', Journal of Business Ethics 85(1), 77-92.

Kennedy, L.: 1999, 'Co-Operating for Survival: Tannery Pollution and Joint Action in the Palar Valley', World Development 27(9), 1673-1691.

Kennedy, L.: 2006, 'Improving Environmental Performance of Small Firms through Joint Action: Indian Tannery Clusters', in A. Blackman (ed.), Small Firms 
and the Environment in Developing Countries - Collective Action and Collective Impacts (Resources for the Future Press, Washington, DC), pp. 112-128.

Khan, A.: 2007, Power, Policy and the Discourse on Child Labour in the Football Manufacturing Industry of Sialkot (Oxford University Press, Karachi, Pakistan).

Kolk, A. and R. V. Tulder: 2001, 'Multinationality and Corporate Ethics - Codes of Conduct in the Sporting Goods Industry', Journal of International Business Studies 32(2), 267-283.

Kolk, A. and R. V. Tulder: 2002, 'The Effectiveness of SelfRegulation: Corporate Codes of Conduct and Child Labor', European Management Journal 20(3), 260-271.

Kolk, A. and R. V. Tulder: 2004, 'Ethics in International Business: Multinational Approaches to Child Labor', Journal of World Business 39(1), 49-60.

Lim, S. J. and J. Phillips: 2008, 'Embedded CSR Values the Global Footwear Industry's Evolving Governance Structure', Journal of Business Ethics 81(3), 143-156.

Locke, R. M., F. Qin and A. Brause: 2007, 'Does Monitoring Improve Labor Standards? Lessons from Nike', Industrial and Labor Relations Review 61(1), 3-31.

Locke, R. M. and M. Romis: 2007, 'Improving Work Conditions in Global Supply Chains', MIT Sloan Management Review 48(2), 54-62.

Locke, R. M., et al.: 2009, 'Virtue Out of Necessity: Compliance, Commitment, and the Improvement of Labor Standards', Politics \& Society 37(3), 319-351.

Lund-Thomsen, P.: 2008, 'The Global Sourcing and Codes of Conduct Debate: Five Myths and Five Recommendations', Development and Change 39(6), 1005-1018.

Lund-Thomsen, P. and K. Nadvi: 2009, Global Value Chains, Local Clusters, and Corporate Social Responsibility: a Comparative Assessment of the Sports Goods Clusters in Sialkot, Pakistan and Jalandhar, India. Technical Paper 17 (Industrial Policy and Private Sector Development Branch, United Nations Industrial Development Organisation, Vienna, Austria).

Lund-Thomsen, P. and K. Nadvi: 2010, 'Global Value Chains, Local Collective Action, and Corporate Social Responsibility: A Review of Evidence', Business Strategy and the Environment 19(1), 1-13.

Nadvi K. 1999a: 'Collective Efficiency and Collective Failure: The Response of the Sialkot Surgical Instrument Cluster to Global Quality Pressures', World Development 27(9), 1605-1626.

Nadvi, K.: 1999b, Facing the New Competition: Business Associations in Developing Country Industrial Clusters. Working Paper 103, International Institute for Labour Studies, Geneva.

Nadvi, K.: 2004, 'The Effect of Global Standards on Local Producers: A Pakistani Case study', in $\mathrm{H}$. Schmitz (ed.), Local Enterprises in the Global Economy:
Issues of Governance and Upgrading (Edward Elgar, Cheltenham, UK), pp. 297-325.

Nadvi, K.: 2008, 'Global Standards, Global Governance and the Organisation of Global Value Chains', Journal of Economic Geography 8(3), 323-343.

Nadvi, K. and S. Barrientos: 2004, Industrial Clusters and Poverty Alleviation: Mapping Links and Developing a Methodology for Poverty and Social Impact Assessment of Cluster Development Initiatives. Working Paper, United Nations Industrial Development Organization, Vienna, Austria.

Neilson, J. and B. Pritchard: 2009, Value Chain Struggles: Institutions and Governance in the Plantations of South India (Wiley-Blackwell, Glouchester, UK).

Nelson, V., A. Martin and J. Ewert: 2007, 'The Impacts of Codes of Practice on Worker Livelihoods', Journal of Corporate Citizenship 28, 61-78.

Organization for Economic Cooperation, Development: 1999, Boosting Innovation: The Cluster Approach (OECD, Paris, France).

Pietrobelli, C. and R. Rabellotti: 2007, Upgrading to Compete. Global Value Chains, SMEs and Clusters in Latin America (Harvard University Press/Cambridge University Press, Cambridge, MA).

Ponte, S. and P. Gibbon: 2005, 'Quality Standards Conventions, and the Governance of Global Value Chains', Economy and Society 34(1), 1-31.

Porter, M. E.: 1998, 'Clusters and the New Economics of Competition', Harvard Business Review 76(6), 77-90.

Riisgaard, L., S. Bolwig, S. Ponte, A. du Toit, N. Halberg and F. Matose: 2010, 'Integrating Poverty and Environmental Concerns into Value-Chain Analysis: A Strategic Framework and Practical Guide', Development Policy Review 28(2), 195-216.

Ruwanpura, K. N. and L. Roncolato: 2006, 'Child Rights: An Enabling or Disabling Right? The Nexus between Child Labour and Poverty in Bangladesh', Journal of Developing Societies 22(4), 359-378.

Schmitz, H.: 1995, 'Small Shoemakers and Fordist Giants: Tale of a Supercluster', World Development 23(1), 9-28.

Schmitz, H.: 2004, Local Enterprises in the Global Economy: Issues of Governance and Upgrading (Edward Elgar, Cheltenham, UK).

Schmitz, H.: 2006, 'Learning and Earning in Global Garment Chains', European Journal of Development Research 18(4), 546-571.

Schmitz, H. and K. Nadvi: 1999, 'Clustering and Industrialization: Special Issue', World Development 27(9), 1503-1514.

Tallontire, A.: 2007, 'CSR and Regulation: Towards a Framework for Understanding Private Standards Initiatives in the Agri-Food Chain', Third World Quarterly 28(4), 775-791. 
Tallontire, A. and P. Greenhalgh: 2005, Establishing CSR Drivers in Agri-business. Final Report for Foreign Investment Advisory Service, International Finance Corporation and World Bank (Natural Resources Institute, Greenwich, UK).

Tewari, M. and P. Pillai: 2005, 'Global Standards and the Dynamics of Compliance in the Indian Leather Industry', Oxford Development Studies 33(2), 245-267.

Tulder, R. V., J. Wijk and A. Kolk: 2009, 'From Chain Liability to Chain Responsibility - MNE Approaches to Implement Safety and Health Codes in International Supply Chains', Journal of Business Ethics 89(Suppl 2), 399-412.

Wijen, F. and S. Ansari: 2007, 'Overcoming Inaction Through Collective Institutional Entrepreneurship: Insights from Regime Theory', Organization Studies 28(7), 1079-1100.
Peter Lund-Thomsen

Center for Business and Development Studies, Center for Corporate Social Responsibility, Copenhagen Business School, Porcelanshaven 18A, 2000 Frederiksberg, Denmark E-mail:plt.ikl@cbs.dk

Khalid Nadvi School of Environment and Development, University of Manchester, Manchester M13 9PL, U.K. E-mail:khalid.nadvi@manchester.ac.uk 